\title{
Spatial patterns and determinants of fertility levels among women of childbearing age in Nigeria
}

\author{
Oluwayemisi O Alaba ${ }^{a b *}$ (D), Olusanya E Olubusoye ${ }^{b}$ and JO Olaomi ${ }^{b}$ \\ ${ }^{a}$ Department of Statistics, University of Ibadan, Ibadan, Nigeria \\ ${ }^{b}$ Department of Statistics, University of South Africa, Roodeport, South Africa \\ *Corresponding author, email: oluwayemisioyeronke@yahoo.com
}

Background: Despite aggressive measures to control the population in Nigeria, the population of Nigeria still remains worrisome. Increased birth rates have significantly contributed to Nigeria being referred to as the most populous country in Africa. This study analyses spatial patterns and contributory factors to fertility levels in different states in Nigeria.

Method: The 2013 Nigerian Demographic Health Survey (NDHS) data were used to investigate the determinants of fertility levels in Nigeria using the geo-additive model. The fertility levels were considered as count data. Negative Binomial distribution was used to handle overdispersion of the dependent variable. Spatial effects were used to identify the hotspots for high fertility levels. Inference was a fully Bayesian approach. Results were presented within 95\% credible Interval (CI).

Results: Secondary or higher level of education of the mother, Yoruba ethnicity, Christianity, family planning use, higher wealth index, previous Caesarean birth were all factors associated with lower fertility levels in Nigeria. Age at first birth, staying in rural place of residence, the number of daughters in a household, being gainfully employed, married and living with a partner, community and household effects contribute to the high fertility patterns in Nigeria. The hotspots for high fertility in Nigeria are Kano, Yobe, Benue, Edo and Bayelsa states.

Conclusion: State-specific policies need to be developed to address fertility levels in Nigeria.

Keywords: Bayesian analysis, count data, fertility, Nigeria, spatial analysis

\section{Introduction}

Fertility trends in most of the developed world in the late 1990s showed a substantial decline to two children or fewer from the traditional six children per woman. ${ }^{1,2}$ Despite the declining fertility rate, the total fertility rate (TFR) is still high in sub-Saharan Africa. In sub-Saharan Africa, the TFR is five children per woman on the average whereas countries like Chad, Mali, Niger and Nigeria record over six to seven children per woman. ${ }^{3}$ Among sub-Saharan African countries, Nigeria is generally known as the most populous country in Africa with a population of over 174 million in 2013, which is approximately one-sixth of the total African population. ${ }^{3}$ Nigeria is one of the sub-Saharan African countries with the fastest growing populations with a TFR of 6.8 in the early 1980s and 1990, 5.9 in 1991, 5.4 in 1994 and 5.2 in 1999. In 2003, the TFR was 5.7; this dropped to 5.5 in 2013, which depicts a decline in the fertility pattern. However, this is relatively high compared with Latin America and Asia where fertility declined from 5.9 to 2.6 and less rapidly in North Africa and Western Asia from 6.6 to 3.5 births per woman. The transition is slowest in sub-Saharan Africa, especially in Nigeria where fertility declined by 1.3 only, from 6.8 to 5.5 children per woman. ${ }^{4}$

A high fertility rate, which is defined as a TFR of 5.0 or higher, is characterised among others by health risks for children and their mothers, food insecurity, high unemployment rate, slow economic growth and environmental threats. ${ }^{5}$ Considerable evidence from economically advanced countries indicates that reduced fertility rates foster economic development and social well-being of the citizenry. The fertility level is undoubtedly conditioned by the cultural, health, political, demographic and socio-economic setting. ${ }^{6-9}$ Proximate and socio-demographic determinants of fertility such as current marital status, polygyny, age at first marriage, first sexual intercourse and recent sexual activity, postpartum amenorrhea, abstinence, age at first birth as well as use of contraceptives, education, place of residence and wealth index have been found to significantly affect fertility patterns. ${ }^{10}$

Model-based analyses are becoming important sources of global information, largely because of the absence of reliable nationallevel empirical data in most developing countries like Nigeria. Fertility pattern is usually measured by the number of children ever born (CEB), which using count data is a measure of a woman's lifetime fertility. ${ }^{9}$ The data-collection method of the Nigeria Demographic Health Survey (NDHS) followed a threestage stratified design. Dependency is inevitable for observations in the same clusters because of shared beliefs and norms within the same community, which may vary from one community to the other, which in turn affects fertility behaviour. ${ }^{11,12}$ Fertility levels maybe spatially clustered because fertility decisions spread across space. Communities that share boundaries are likely to display similar fertility behaviour, and thus spatial autocorrelation is possible. ${ }^{9}$ Trivialising spatial effects of fertility may lead to misleading conclusions. For instance, Akpa and Ikpotokin ${ }^{13}$ considered both proximate and some sociodemographic factors that affect fertility in Nigeria using the Poisson regression model without taking cognisance of the spatial effects. Similar studies have been considered on determinants of fertility in Nigeria. ${ }^{14,15}$ However, in this study, the availability of geo-referenced data in NDHS allows the exploration of the geographical variation effects of fertility in Nigeria. The geo-additive model, which incorporates spatially structured effects and different effects of the variables as well as the nature of the dependent variable is considered suitable for this study. 


\section{Methods}

\section{Data}

The data used for this study were drawn from the 2013 NDHS, which is a nationally representative sample. The 2013 NDHS was conducted by the National Population Commission (NPC) with funding support from the US Agency for International Development (USAID), the United Nations Population Fund (UNFPA), and the United Kingdom Department for International Development (DFID). Technical support was provided by ICF International. The 2013 NDHS sample was selected using a threestage stratified design consisting of 904 clusters, 372 in urban areas and 532 in rural areas. In the 2013 NDHS dataset, 40320 households were selected, of which 38522 were interviewed. Data analysed were from 39902 women of childbearing age (15-49 years). Although different covariates on population and health issues in Nigeria were presented in the comprehensive and well-detailed dataset, we focused on total CEB as the dependent variable. The mean of the total CEB is 4.35, variance $=6.786$, skewness $=0.828$, range $=17$. The data are overdispersed. ${ }^{16}$ Equidispersion is often a mirage in real-life studies; inappropriate imposition of a Poisson regression model will underestimate and overstate the significance of regression parameters. ${ }^{17}$ Negative binomial distribution has been suggested as an alternative to Poisson regression when the data are overdispersed..$^{18-20}$

The choice of explanatory variables was guided by the literature. Kazembe, ${ }^{9}$ on modelling fertility in Malawian women, which was adapted in explaining fertility in Nigeria, includes: educational attainment, ethnicity, marital status, religion, place of residence, wealth index, family planning, number of daughters, number of dead children, method of delivery, work status, region, partner education, age at first birth and body mass index (BMI). All the categorical variables were effect coded. The clusters, 36 states and the Federal Capital Territory (FCT), were considered.

\section{Data analysis}

We used negative binomial distribution as a way out of overdispersed count data within the framework of generalised linear models to investigate fertility patterns in Nigeria. ${ }^{20} \mathrm{We}$ modelled fertility patterns using the number of children ever born, where CEB comprises count data, to investigate the fertility patterns. ${ }^{9}$ Given a set of observations $\left(y_{i j k}, x_{i j k}\right)$ where $y_{i j k}$ is the total number of CEB for the $k$ th woman in the $j$ th community in the $i$ th state and $x_{i j k}$ is the corresponding vector of covariates and $\gamma$ is the vector of regression parameters of the linear effect of categorical covariates, let us suppose some of the covariates are nonlinear: $f_{i j k}$ and $f_{\text {spat }}$ is the nonlinear effect of state $i$ for $i=1,2, \ldots 37$ where the women of childbearing age reside. Then $y_{i j k^{\prime}}$ that is, CEB as a count variable, can be modelled using a semiparametric spatial Poisson regression model. However, because the data are overdispersed we use negative binomial distribution. ${ }^{18-20}$ The uncorrelated random effect can be controlled for using the community, which is given by $b_{i j}$. The semiparametric structured additive predictor is then given by:

$$
y_{i j k} / \gamma, b_{i j k} \sim N B\left(\mu_{i j k}\right)
$$

$$
\text { Where the predictor } \eta_{i j k}=x_{i j k}^{\prime} \gamma+f_{i j k}\left(x_{i j k}\right)+f_{s p a t}+b_{i j}
$$

Inference was a fully Bayesian approach based on Markov Chain Monte Carlo (MCMC) simulation techniques for the unknown posterior distribution. For the continuous/metrical covariates, we assume penalized splines (P-spline) prior with second-order random walk to ensure flexibility. ${ }^{12,21}$ A suitable choice of diffuse prior is assumed for the fixed effect parameters $\gamma$. The Markov random field prior $^{22}$ allows a binary adjacency structure such that areas that share boundaries, which we assume to have similar patterns, are assigned a weight of 1 , otherwise zero is given. The random effects were modelled from exchangeable normal priors to account for heterogeneity. The model was implemented in Bayes $X$ version 2.1. ${ }^{23}$

\section{Results}

The results of the categorical covariates of the posterior negative binomial regression are presented in Table 1. The table presents the means, standard deviations and $95 \% \mathrm{Cl}$. Findings indicated a significant relationship between high fertility in the north-east and the Hausa tribe. For instance, the results revealed that women of childbearing age in the north-eastern region have a higher risk for having more children (mean $0.010, \mathrm{Cl} 0.006,0.050$ ) as well as the Hausa tribe (mean $0.017, \mathrm{Cl} 0.005,0.038$ ). Women of childbearing age who lived in the south-western region tend to have relatively fewer children than women in the north-central region. Women of childbearing age who dwelt in the rural area have a desire for more children than women in the urban area (mean 0.013, $\mathrm{Cl} 0.003$, 0.023). There is distinct association between fertility patterns and education. Higher education of women of childbearing age is inversely related to high fertility level. For instance, findings showed that women who had at least secondary education (mean $-0.076, \mathrm{Cl}-0.09,-0.063)$ showed less desire for more children relative to women who had no formal education. Similar results were obtained for partner's educational level. Contrary to expectations, the rich/richest wealth index of the mother showed a significant association with low fertility level. Mothers of childbearing age who were of the Islamic faith were more likely to have more children than those women who practised traditional religion or had no religion. Women who practised Christianity (mean $-0.031, \mathrm{Cl}-0.051,-0.012$ ) were significantly more likely to have lower fertility levels than women with no religion or those who practised traditional religion. Use of any type of family planning methods (mean $-0.040, \mathrm{Cl}-0.048,-0.031$ ) showed a significant negative effect on the number of children a woman will have compared with a woman who is not on any family planning method. Women who are married and living with partners as expected had more children relative to other marital status such as single, widowed or divorced. Marriage increased the risk of conception, which in turn increased the fertility level of women. The working status of a mother of childbearing age reflected a positive significant association with her fertility level. Working mothers are likely to have more children than women who are not working. The mode of delivery suggested that fertility level will decline in women who had previous Caesarean section compared

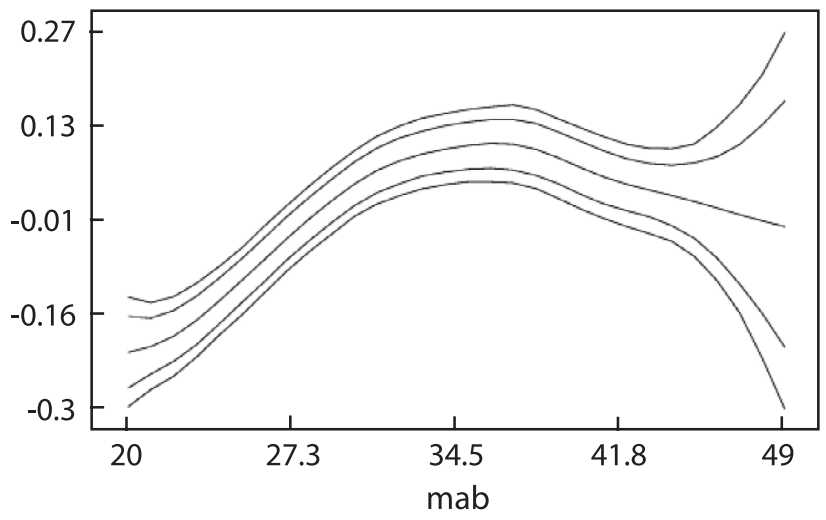

Figure1: Nonlinear effect of mother's age at birth (mab) on fertility. 
Table 1: Posterior estimates within 95\% credible interval (Cl)

\begin{tabular}{|c|c|c|c|}
\hline Variable & Mean & SD & $95 \% \mathrm{Cl}$ \\
\hline Constant & 1.101 & 0.083 & $(0.913,1.260)$ \\
\hline \multicolumn{4}{|l|}{ Region } \\
\hline North-central (ref.) & 0 & & \\
\hline North-east & 0.010 & 0.024 & $(0.006,0.050)^{*}$ \\
\hline North-west & -0.098 & 0.025 & $(-0.074,0.029)$ \\
\hline South-east & 0.045 & 0.027 & $(-0.004,0.100)$ \\
\hline South-west & -0.064 & 0.022 & $(-0.016,0.070)$ \\
\hline South-south & 0.024 & 0.026 & $(-0.050,-0.004)^{* *}$ \\
\hline \multicolumn{4}{|l|}{ Place of residence } \\
\hline Urban (ref.) & 0 & & \\
\hline Rural & 0.013 & 0.005 & $(0.003,0.023)^{*}$ \\
\hline \multicolumn{4}{|l|}{ Mother's educational attainment } \\
\hline No education (ref.) & 0 & & \\
\hline Primary & 0.085 & 0.006 & $(0.072,0.097)^{*}$ \\
\hline Secondary & -0.076 & 0.007 & $(-0.090,-0.063)^{* *}$ \\
\hline Higher & -0.123 & 0.013 & $(-0.148,-0.097)^{* *}$ \\
\hline \multicolumn{4}{|l|}{ Ethnicity } \\
\hline Other ethnic groups (ref.) & 0 & & \\
\hline Yoruba & -0.039 & 0.014 & $(-0.065,-0.011)^{* *}$ \\
\hline Ibo & 0.012 & 0.017 & $(-0.023,0.043)$ \\
\hline Hausa & 0.017 & 0.011 & $(0.005,0.038)$ \\
\hline \multicolumn{4}{|l|}{ Wealth index } \\
\hline Poorest/poorer (ref.) & 0 & & \\
\hline Middle class & 0.006 & 0.005 & $(-0.004,0.016)$ \\
\hline Richer/richest & -0.009 & 0.007 & $(-0.004,-0.023)^{*}$ \\
\hline \multicolumn{4}{|l|}{ Religion } \\
\hline None/traditional (ref.) & 0 & & \\
\hline Christianity & -0.031 & 0.010 & $(-0.051,-0.012)^{* *}$ \\
\hline Islam & 0.053 & 0.011 & $(0.034,0.077)^{*}$ \\
\hline \multicolumn{4}{|l|}{ Family planning } \\
\hline No method (ref.) & 0 & & \\
\hline Folkloric/traditional mode & -0.040 & 0.004 & $(-0.048,-0.031)^{* *}$ \\
\hline \multicolumn{4}{|l|}{ Marital status } \\
\hline Other (ref.) & 0 & & \\
\hline Married and living with partner & 0.091 & 0.008 & $(0.076,0.106)^{*}$ \\
\hline \multicolumn{4}{|l|}{ Mother's working status } \\
\hline Not working (ref.) & 0 & & \\
\hline Working & 0.058 & 0.003 & $(0.052,0.064)^{*}$ \\
\hline \multicolumn{4}{|l|}{ Mode of delivery } \\
\hline Normal delivery (ref.) & 0 & & \\
\hline Caesarean section & -0.049 & 0.012 & $(0.072,0.026)^{*}$ \\
\hline \multicolumn{4}{|l|}{ Sex of children } \\
\hline Boys (ref.) & 0 & & \\
\hline Girls & 0.277 & 0.003 & $(0.271,0.283)^{*}$ \\
\hline
\end{tabular}

*Positively significant.

${ }^{* *}$ Negatively significant.

with women who had a normal delivery. The sex of the children is another important factor. Women who had only daughters (mean $0.277, \mathrm{Cl} 0.271,0.283$ ) are likely to have more children than women who have at least one son.
The result of the nonlinear effects of the mother's age at birth and its effect on fertility at $95 \% \mathrm{Cl}$ is shown in Figure 1. Rigid assumption of the linear effect of mother's age at birth on number of children could have led to statistical error. The result confirmed the nonlinear relationship between mother's age at birth and the fertility patterns. There was an increase as women advanced in age; fertility peaked around 35 years of age. However, a steady decline in fertility started around 40 years of age. As the age of women of childbearing age advanced, the fertility patterns declined, and a rapid drop was noticed from around 45 years of age.

The $95 \% \mathrm{Cl}$ of fertility differential is presented in Figure 2, while Figure 3 is the corresponding labelled map of Nigeria. States shown in white denote a significant positive association with fertility while those in black denote a significant negative association with fertility. Those in grey denote states with insignificant fertility patterns at $95 \% \mathrm{Cl}$. Yobe, Kano, Benue, Edo and Bayelsa states had significant higher likelihood for fertility. Kebbi, Niger, Kwara, Oyo and Lagos states exhibit significant lower effect for fertility.

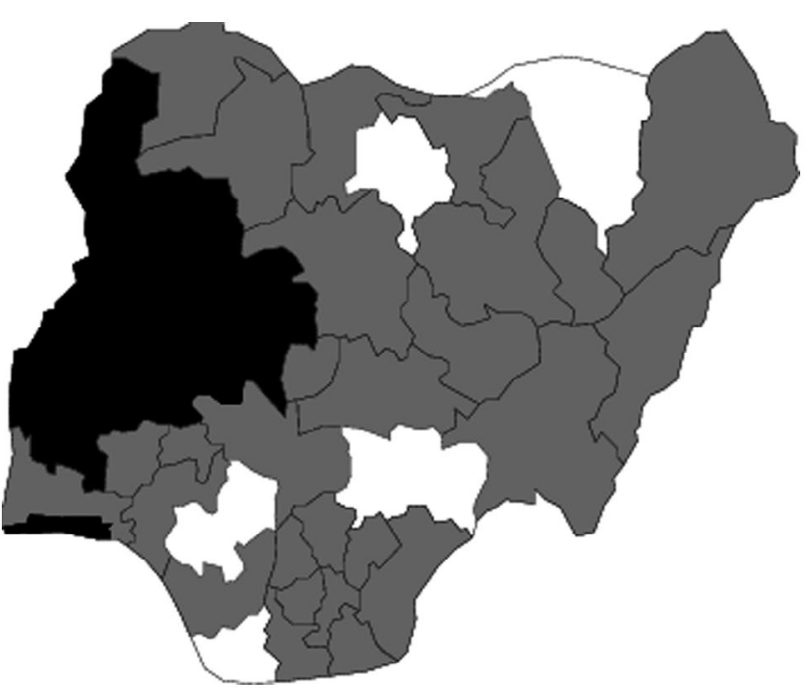

Figure 2: Spatial spread of fertility in Nigeria $(95 \% \mathrm{Cl})$.

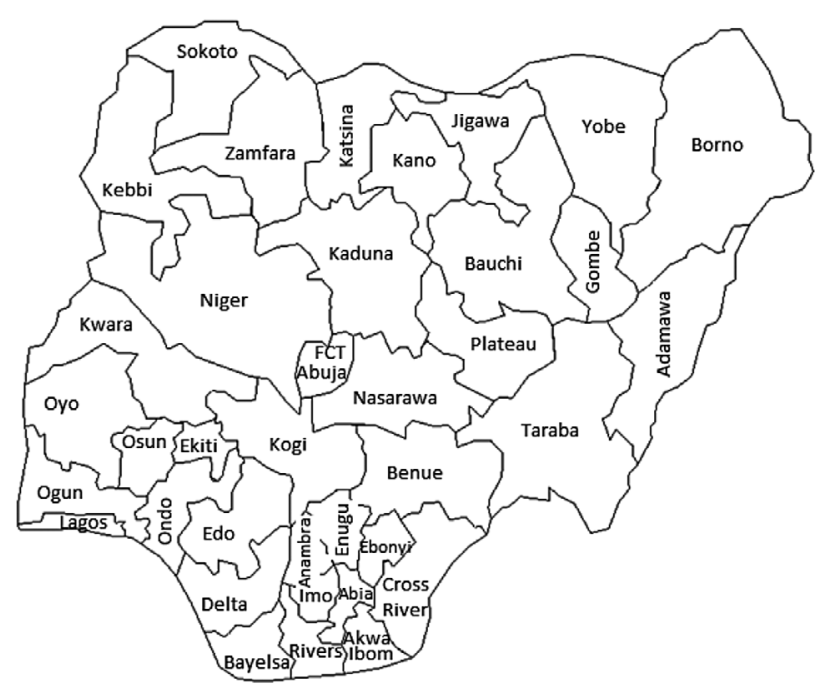

Figure 3: Labelled map of Nigeria. 


\section{Discussion of results}

The objective of this study was to investigate spatial patterns and factors associated with the fertility levels of women of childbearing age in Nigeria. Fertility level is a crucial developmental factor that is related to growth of the economy ${ }^{24,25}$ as well as child and maternal health. ${ }^{9,26}$ Notable literature abounds on fertility in Nigeria; however, this article contributes to the existing literature. The negative binomial model was used to handle overdispersion after running descriptive statistics on the fertility levels of women, which naturally comprises count data.

The geo-additive model was used to simultaneously capture the continuous nature of the dependent variable, the continuous and categorical forms of the independent variables as well as the spatial and random effects on fertility levels. The posterior estimates of the categorical variables show that women who are residents of rural areas are more susceptible to high fertility levels than their counterparts in rural areas. Low or no education, inaccessibility to basic amenities, early marriage, infant and child mortality, no contraceptive use, and need for labour for agricultural practices are major determinants of high fertility levels in rural areas. ${ }^{27,28}$ In Nigeria, in addition to the factors already stated, high fertility patterns in the rural areas have been found to be associated with patriarchal and hierarchical households, and polygamy in which women compete regarding the number of children. ${ }^{4}$ Although Nigerian civil law does not recognise polygamy, 12 out of 36 states are governed by Sharia law, which encourages the practice of polygamy. ${ }^{16}$ In Nigeria, a larger percentage of women in rural areas believe that contraceptives destroy the womb and abortion is murder. ${ }^{29}$ This belief and the illegality of abortion gives rise to unwanted children with a resultant effect of high fertility in rural areas.

The underpinning effect of education on fertility levels cannot be overemphasised. Leon ${ }^{30}$ found that education is an important determinant of fertility with several causal relationships from a theoretical perspective. Schultz ${ }^{31}$ has long established a strong negative association between a mother's education and fertility. In fact, female education has been proposed as a major means of reducing fertility and population growth. ${ }^{2,32,33}$ The greater the educational level of a woman, the lower her fertility level relative to women without education, which further corroborates our findings in this study. ${ }^{34-36}$

Akpa and Ikpotokin ${ }^{13}$ opined that fertility levels in Nigeria are associated with ethnicity. They found that Hausa and Ibo women have higher fertility than those from the minority ethnic groups. Age at first marriage, education and socio-economic factors are some of the contributory factors to the decline in fertility among the Yoruba tribe relative to the Hausa and Ibo tribes. ${ }^{37,38}$ Ajala $^{39}$ found that women in the richest quintile households are likely to give their children quality education, thereby giving birth to just the number of children they can cater for. However, some women from the poor and poorer quintile actually see childbearing as a means of acquiring cheap labour, especially for agricultural purposes. Skirbekk ${ }^{10}$ found that high income/wealth, high occupation/social class favours fewer children relative to other classes. Religion plays a significant role in shaping people's beliefs and values. In Islam, polygamy, conservatism, association of contraception with prostitution, and a large age gap between husbands and wives explains the high fertility among Muslims. ${ }^{40-42}$ Differences in fertility levels for Christianity and Islam can be linked to mean age at marriage. Christianity reduces the desire for high fertility, which can be explained by the fact that modern Christianity encourages monogamy. ${ }^{41}$
Any form of contraception inhibits the natural process of procreation. Family planning would prevent at least 53 million unintended pregnancies each year, thereby causing a decline in fertility levels. ${ }^{12}$ One would not be surprised that a married woman who stays with her spouse will be at higher risk of having more children, as shown in our results. ${ }^{7}$ Mothers whose first delivery was through Caesarean section do not desire more than three children. The desire for more children is high for women who have only daughters. In fact, $\mathrm{Ali}^{34}$ concluded that until an African woman has at least one son, her desire for children is incomplete.

\section{Conclusion}

This study has broadened our knowledge on the spatial patterns and factors associated with fertility levels among women of childbearing age in Nigeria. It is hoped that the identified factors will assist in intervention programmes directed towards a downward shift in the fertility levels in Nigeria. The findings can be used for developing integrated support tools for the government, health policy-makers and international agencies interested in fertility-related issues.

Acknowledgements - The authors appreciate the permission granted by the Measure Demographic and Health Survey to use the data analysed in this study.

\section{ORCID}

Oluwayemisi O Alaba (iD http://orcid.org/0000-0002-1376-606X Olusanya E Olubusoye (iD http://orcid.org/0000-0001-8672-7822

\section{References}

1. Bongaarts J. Household size and composition in the developing world. Policy Research Division, Population Council. 2001;144.

2. Bongaarts J. The causes of educational differences in fertility in Sub-Saharan Africa. Vienna Yearbook of Popul Res. 2010;8:31-50. https://doi.org/10.1553/populationyearbook

3. United Nations. World fertility report 2013: Fertility at the extremes. Department of Economic and Social Affairs, Population Division. 2014.

4. Makinwa-Adebusoye, PK, Feyisetan BJ. The quantum and tempo of fertility in Nigeria. In: Macro International Inc. Fertility trends and determinants in six African Countries, DHS regional analysis for anglophone Africa. Calverton, Maryland: Macro International; 2001. p. 41-86.

5. Casterline JB. Wanted fertility, unwanted fertility, and fertility decline: A fresh assessment. Paper presented at the annual meeting of the population association of America; 2010, Dallas, Texas.

6. McCarthy J, Oni G. Desired Family Size and Its Determinants Among Urban Nigerian Women: A Two-Stage Analysis. Demography. 1987;24(2):279-90. https://doi.org/10.2307/2061635

7. Anh TS, Knodel J, Lam D, et al. Family Size and Children's Education in Vietnam. Demography. 1998;35(1):57-70. https://doi. org/10.2307/3004027

8. Singh P. An introductory text on demography. Dabco Investments Limited, Kaduna Nigeria. 2002;2:53-65.

9. Kazembe LN. Modelling individual fertility levels in Malawian women: a spatial semiparametric regression model. Stat Methods Appl. 2009;18(2):237-55. https://doi.org/10.1007/s10260-007-0076-2

10. Skirbekk V. Fertility trends by social status. Demogr Res. 2008;18(5):145-80. https://doi.org/10.4054/DemRes.2008.18.5

11. Entwisle B, Casterline JB, Sayed HAA. Villages as Contexts for Contraceptive Behavior in Rural Egypt. Am Soc Rev. 1989;54:1019-34. https://doi.org/10.2307/2095721

12. Alaba OO, Olaomi JO, Olubusoye OE. Spatial pattern of unmet need of family planning in Nigeria. S Afr Fam Pract J. 2015;57(5):306-12.

13. Akpa OM, Ikpotokin O. Modelling the determinants of fertility among women of childbearing age in Nigeria: analysis using generalized linear modelling approach. Int J Humanit Soc Sci. 2011;2(18):167. 
14. Akpotu NE. Education as correlate of fertility among families in Southern Nigeria. J Human Ecol. 2008;23(1):65-70.

15. Jegede AS, Fayemiwo AS. Cultural and ethical challenges of assisted reproductive technologies in the management of infertility among the yoruba of Southwestern Nigeria. Afr J Reprod Health. 2010;14(2):115-27.

16. Akpan-Iquot IE. Traditional marriage in Nigeria: Polygamy, 2000 [cited 2014 Nov 21]. Available from: www.nigerianwomenworld.com.

17. Ismail $\mathrm{N}$, Zamani $\mathrm{H}$. Estimation of claim count data using negative binomial, generalized Poisson, zero-inflated negative binomial and zero-inflated generalized Poisson regression models. Casualty Actuar Soc E-Forum. 2013;1-28.

18. Paternoster R. Brame $R$ multiple routes to delinquency? A test of developmental and general theories of crime. Criminology. 1997;35:45-84.

19. Osgood D. Wayne. Poisson-based regression analysis of aggregate crime rates. J Quant Criminol. 2000;16:21-43. https://doi. org/10.1023/A:1007521427059

20. Ismail N, Jemain AA. Handling overdispersion with negative binomial and generalized poisson regression models. Casualty Actuar Soc Forum. 2007;103-58.

21. Fahrmeir $L$, Lang $S$. Bayesian inference for generalized additive mixed models based on Markov random field priors. J Royal Stat Soc C. 2001;50:201-20. https://doi.org/10.1111/1467-9876.00229

22. Besag J, York Jeremy, Mollie A. Bayesian image restoration with two applications in spatial statistics. Annals Inst Stat Math. 1991;43(1):1-20. https://doi.org/10.1007/BF00116466

23. Belitz C, Brezger A, Kneib T, et al. BayesX software for Bayesian inference in structured additive regression models. 2012. Available from: www.stat.uni-muenchen.de/ bayesx

24. Birdsall N, Kelley AC, Sinding S. Population matters: Demographic change, economic growth, and poverty in the developing world. London: Oxford University Press; 2003.

25. Orsal DDK, Goldstein JR. The Increasing Importance of Economic Conditions on Fertility. Max Planck Institute for Demographic Research, Germany; 2010.

26. Shen C, Williamson JB. Maternal mortality, women's status, and economic dependency in less developed countries: a cross national analysis. Soc Sci Med. 1999;49:197-214. https://doi.org/10.1016/ S0277-9536(99)00112-4

27. Martine G, Alves JE, Cavenaghi S. Urbanization and fertility decline: cashing in on structural change IIED's Human Settlements Group Working Paper, London. ISBN-978-1-84369-995-8.
28. Shapiro D, Tambashi BO. Fertility transition in urban and rural areas of sub-Saharan Africa: preliminary evidence of a three stage process. J Afr Policy Stud. 2002;8(2\&3):103-27.

29. Ushie MA, Agba AM, Ogaboh O, et al. Socio-cultural and economic determinants of fertility differentials in rural and urban cross rivers state, Nigeria. J Geogr Regional Plan. 2011;4(7):383-91.

30. Leon A. The effect of education on fertility: evidence from compulsory schooling laws. Pittsburgh: University of Pittsburgh Press; 2004.

31. Schultz TP. 1993. Investments in the schooling and health of women and men: quantities and returns. J Hum Resour. 1993;28(4):694-94.

32. Shapiro D, Gebreselassie T. Falling and Stalling Fertility in Sub-Saharan Africa. Revised version of paper presented at the International Union for the Scientific Study of Population International Seminar on Human Fertility in Africa:Trends in the Last Decade and Prospects for Change, Cape Coast, Ghana; 2008, Sep 16-18.

33. United Nations. Department of economic and social affairs, The world's women 2010: Trends and statistics. Available from: http:// unstats.un.org/unsd/demographic/products/Worldswomen/ WW2010pub.htm

34. Ali SM. Determinants of family size preferences in Pakistan. Pakistan Dev Rev. 1989;28(3):207-31.

35. Angeles G, Guilkey DK. The Effects of Education and Family Planning Programs on Fertility in Indonesia. Econ Dev Cult Chang. 2005;54(1):165-201. https://doi.org/10.1086/431261

36. Shapiro D. Women's education and fertility transition in sub-saharan Africa; 2011.

37. Orubuloye IO. Fertility transition in southwest Nigeria in the era of structural adjustment. Paper presented at the IUSSP Seminar on Reproductive Change in sub-Saharan Africa, Nairobi, Kenya; 1998 Nov 2-4.

38. Oyefara JO. Age at first birth and fertility differentials among women in Osun State, Nigeria. Eur Sci J. 2010;8(16):139-50.

39. Ajala AO. Factors associated with teenage pregnancy and fertility in Nigeria. J Econ Sustain Dev. 2014;5(2):1222-40.

40. Akintunde MO, Lawal MO, Simeon O. Religious roles in fertility behaviour among the residents of akinyele local government, Oyo State, Nigeria. Int J Econ Management Soc Sci. 2013;2(6):455-62.

41. Gayawan E. Spatial Pattern and Determinants of Age at Marriage in Nigeria Using a Geo-Additive Survival Model. Math Popul Stud. 2014;21:112-24. https://doi.org/10.1080/08898480.2014.892336

42. Mazrui AA. Islamic doctrine and the politics of induced fertility change: an African perspective. Int J Econ Management Soc Sci. 1994;2(6):455-62. 